\title{
Study of Sorghum bicolor L. for bioethanol production in the conditions of the South-East of Kazakhstan
}

\author{
Iskakova K.M. ${ }^{1}$, Anapiyayev B.B. ${ }^{1 *}$, Beisenbek E.B. ${ }^{1}$, Omarova A.S. ${ }^{2}$, \\ Sagimbaeva A.M. ${ }^{1}$ \\ ${ }^{1}$ Institute of Chemical and Biological Technology, KazNRTU named after K.I. Satpayev, \\ Almaty, Kazakhstan \\ ${ }^{2}$ Kazakh Research Institute of Agriculture and Plant Growing, Almalybak, Kazakhstan \\ *e-mail: bak_anapiyayev@mail.ru
}

Sorghum is the fifth most important cereal crop after wheat, corn, rice, and barley. Food sorghum is used as food in 30 countries for more than 500 million people living in tropical Africa and South Asia. Forage sorghum is the main ingredient for the preparation of feed for divorce. Sugar sorghum is grown on an industrial scale for the production of syrup, malt, starch, and protein is also a promising raw material for the production of bioethanol. We have conducted studies on the factors affecting the frequency of formation of morphogenic calluses in a culture of somatic sorghum cells grown in the conditions of the South-East of Kazakhstan. During the cultivation of somatic sorghum cells, it was noted that the frequency of callus cell formation and their morphology was significantly influenced by the original genotype of the donor plant. It should be noted that during the cultivation of somatic sorghum cells, the main problem for most genotypes is the phenolic compounds, which are secreted by somatic cells on the seventh to the tenth day of in vitro cultivation. Phenolic compounds are substances of an aromatic nature containing one or more hydroxyl groups of an aromatic ring. In the process of the research it was found that the frequency of callus formation during the cultivation of somatic sorghum cells in vitro grown in the conditions of the South-East of Kazakhstan depends on the original genotype. Also, sorghum genotypes have been found that are capable of forming morphogenic calli that can be used in cell selection for resistance to biotic and abiotic environmental stress factors. Sorghum genotypes with maximum sugar content in cell sap were selected. The maximum sugar content was found in the Kazakhstani 20, Hybrid 3 and Ac-64 genotypes, where the sugar content was $21.4 \%$, $20.7 \%$ and $20.3 \%$, respectively. 